\title{
Penggunaan Analgesik untuk Perawatan Paliatif Pasien Kanker di Poli Paliatif Puskesmas di Kota Surabaya
}

\author{
Fauna Herawati, Vina Fitriana Pratiwi \\ Fakultas Farmasi, Universitas Surabaya \\ Korespondensi: Fauna Herawati \\ Email:fauna@staff.ubaya.ac.id
}

\begin{abstract}
ABSTRAK: Gejala paling umum dan menyedihkan pada pasien kanker adalah nyeri. Oleh karena itu telah dilakukan penelitian yang bertujuan untuk mengetahui profil penggunaan analgesik dan mengevaluasi tingkat kualitas hidup pasien kanker setelah mendapatkan perawatan paliatif dengan alat ukur nyeri berupa kuesioner Brief Pain Inventory (BPI) dan kuesioner Indonesian Barrier Quetionnaire (IBQ). Penelitian ini adalah non eksperimental dengan rancangan penelitian cross sectional. Pasien kanker diberikan alat ukur nyeri dan kuesioner pada saat datang ke Puskesmas. Hasil penelitian menunjukkan bahwa profil penggunaan analgesik pada pasien kanker sudah sesuai dengan ped oman bebas nyeri WHO yaitu step 2 pengobatan untuk nyeri ringan hingga sedang dengan obat yang digunakan kombinasi antara kodein dan parasetamol. Kualitas hidup pasien kanker yang telah menerima perawatan paliatif sudah cukup baik, diukur menggunakan alat ukur untuk penilaian nyeri, BPI, terlihat bahwa nyeri yang dirasakan adalah nyeri ringan dengan hasil penilaian 0,8322 serta diukur menggunakan kuesioner IBQ dapat terlihat hambatan yang terjadi adalah kecil dengan hasil penilaian 0,432.
\end{abstract}

Kata Kunci: Perawatan paliatif, analgesik, Brief Pain Inventory (BPI), Indonesian Barrier Quetionnaire (IBQ)

\begin{abstract}
The most common and distressing symptom in cancer patients is the pain. The objective of this research is to determine the profile of analgesic use and the level of quality of life of cancer patients after treatment using palliative pain questionnaire, Brief Pain Inventory (BPI) and the Indonesian Barrier Questionnaire (IBQ). This is a non-experimental study with cross-sectional study design. Cancer patients are given pain measurement tool and questionnaire when they come to the primary health care center. The results showed that the profile of analgesics uses in cancer patients are compliance with WHO guidelines, i.e pain-free step 2 for the treatment of mild to moderate pain with medications used a combination of codeine and paracetamol. The quality of life of cancer patients who had received palliative care is good enough, its BPI is 0.8322 (the pain experienced is mild) and its IBQ is 0.432 (the barriers is small).
\end{abstract}

Keywords: Palliative care, analgesic, Brief Pain Inventory (BPI), Indonesian Barrier Quetionnaire (IBQ) 


\section{Pendahuluan}

Kanker tertinggi di Indonesia pada perempuan adalah kanker payudara dan kanker leher rahim, sedangkan pada laki-laki adalah kanker paru dan kanker kolorektal [1,2]. Penyakit kanker yang paling banyak diderita adalah penyakit kanker payudara (ca. mammae) sebesar 38,63\% dan kanker leher rahim (ca. serviks) sebanyak 14,31\%, selanjutnya kanker paru 3,18\%. Berdasarkan jenis kelamin, penyakit kanker lebih banyak diderita oleh perempuan sebesar $80,26 \%$, sedangkan laki-laki 17,62\% [3].

Nyeri adalah salah satu gejala yang paling umum dan gejala yang menyedihkan pada pasien kanker [4]. Terdapat 3 puskesmas di Surabaya yang telah diamati dan didapatkan hasil bahwa 36 dari 37 pasien pernah merasakan rasa sakit yang bukan rasa sakit biasa (seperti sakit kepala ringan, terkilir, dan sakit gigi) dan nyeri yang dirasakan adalah nyeri ringan, baik itu nyeri terburuk dalam 24 jam, nyeri teringan dalam 24 jam, rata-rata nyeri yang dirasakan maupun rasa nyeri yang dirasakan saat ini.

Pasien kanker sudah benar mendapatkan analgesik untuk penyembuhan nyeri yang dirasakannya. Sebanyak 94\% pasien kanker di puskesmas merasakan nyeri mereda $\geq 50 \%$ setelah menggunakan analgesik. Delapan dari 37 pasien kanker mengatakan bahwa nyerinya hilang 100\% setelah mengkonsumsi analgesik. Di Amerika sekitar 90\% dari pasien dapat mencapai kontrol nyeri yang baik dengan mengikuti pedoman pengobatan nyeri. Pengurangan nyeri dapat tercapai dengan digunakannya WHO three-step analgesic ladder tentang penggunaan dosis yang tepat berdasarkan tingkatan nyeri [4].

Rasa nyeri yang tidak terkontrol secara bermakna dapat membuat penurunan fungsi tubuh, nafsu makan, tidur, suasana hati dan kualitas hidup [4]. Pasien kanker di Puskesmas di Surabaya merasakan terganggu akan kegiatan sehari-hari, suasana hati, kemampuan berjalan, pekerjaan normal, hubungan dengan orang lain, tidur dan kenyamanan hidupnya saat nyeri ringan terjadi.
Di Puskesmas di Surabaya sebanyak 97\% pasien merasakan rasa sakit yang bukan biasa; gangguan terhadap nyeri ringan yang terjadi. Penelitian ini bertujuan untuk mengukur pengalaman serta hambatan dalam menyatakan nyeri yang dirasakan oleh pasien kanker yang berkunjung ke puskesmas.

\section{Metode}

Penelitian ini merupakan penelitian yang bersifat non-ekperimental (observasional). Penelitian ini menggunakan teknik pengambilan data purposive sampling, dengan observasi terstruktur menggunakan Brief Pain Inventory (BPI) [5] dan kuesioner Indonesian Barrier Questionnaire (IBQ). Pengambilan data dilakukan di Surabaya, di mana terdapat 3 puskesmas yang memiliki program unggulan berupa poli paliatif yaitu Puskesmas Rangkah (Rk), Puskesmas Pacarkeling (Pk) dan Puskesmas Balongsari (Bg). Jumlah populasi pasien kanker pada masing-masing puskesmas yaitu Puskesmas Balongsari sebanyak 20 orang, Puskesmas Pacarkeling sebanyak 40 orang dan Puskesmas Rangkah sebanyak 7 orang.

Pada penelitian ini pasien diberikan 1 alat ukur nyeri Brief Pain Inventory (BPI) dan 1 buah kuesioner Indonesian Barier Questionnaire (IBQ) dan pasien kanker akan diminta untuk menunjukkan seberapa besar rasa nyeri yang dirasakan selama 24 jam terakhir [6] dan hari ini (secara umum) serta mengisi kuesioner tentang hambatan-hambatan yang dirasakan selama pengobatan. Pemberian alat ukur nyeri dan kuesioner ini hanya dilakukan satu kali.

Penelitian ini dilakukan pada penderita dengan diagnosis kanker yang bersedia berpartisipasi dalam penelitian (memberikan persetujuan dengan menandatangani informed consent) di Puskesmas Rangkah (Rk), Pacarkeling (Pk) dan Balongsari (Bg) di Surabaya. Usia minimal pasien adalah 18 tahun. Pada alat ukur BPI terdapat 2 skala yang digunakan yaitu, skala Guttman dan skala Semantic Differential. Skala Likert digunakan pada pertanyaan no 1 apabila jawaban 
'Ya' diberikan skor 1 dan jawaban 'Tidak' diberikan skor 0. Skala Semantic Differential digunakan pada pertanyaan nomor 3 , 4, 5, 6, 8, 9 yaitu pasien memberikan jawaban pada satu garis kontinum yang telah disediakan, bagian kanan garis jawaban menggambarkan rasa nyeri yang sangat buruk dan bagian kiri garis jawaban menggambarkan tidak adanya rasa nyeri. Batasan nilai BPI adalah 1-4 untuk nyeri ringan, 5-6 untuk nyeri sedang dan 7-10 untuk nyeri berat [7,8]. Penentuan skor pada kuesioner IBQ (Indonesian Barrier Questionnaire) menggunakan skala Likert. Setiap jawaban memiliki poin-poin tertentu, yaitu $0=$ sangat tidak setuju, 1 = tidak setuju, 2 = ragu-ragu, 3 = setuju, 4 = sangat setuju, 5 = amat sangat setuju. Skala 0-2 menunjukkan hambatan lemah, skala 3-5 menunjukkan hambatan kuat. Pengolahan dan penyajian data dilakukan secara deskriptif [9].

\section{Hasil}

Terdapat 48 pasien yang datang ke puskesmas selama Januari - Juli 2015, yaitu: 21 orang pasien di Puskesmas Balongsari, 20 orang pasien di Puskesmas Pacarkeling dan 7 orang pasien di Puskesmas Rangkah. Dari 48 pasien tersebut, hanya 36 data pasien dianalisa karena 1 orang tidak bersedia berpartisipasi, 3 orang tidak bisa membaca dan menulis dan 8 orang pasien kanker yang alamatnya tidak sesuai dengan data puskesmas (Tabel 1). Kualitas hidup pasien kanker yang telah menerima perawatan paliatif di puskesmas Rangkah, Pacarkeling dan Balongsari sudah cukup baik, diukur menggunakan alat ukur untuk penilaian skala nyeri BPI (Brief Pain Inventory) terlihat bahwa lebih dari $80 \%$ responden menyatakan nyeri yang dirasakan ringan (skala 1-4); dialami oleh $86,1 \%$ pasien selama 24 jam terakhir (Tabel 2) dan dialami oleh 97,2\% pasien secara umum (kondisi pada hari pengumpulan data) (Tabel 3). Dua puluh dua persen (8/36) pasien menyatakan bahwa setelah minum analgesik rasa nyeri 100\% hilang (benar-benar mereda). Ham- batan pengobatan nyeri dari aspek pasien (kuesioner IBQ) lemah. Hanya 2 pasien (5,6\%) menyatakan "Takut akan konsekuensi penggunaan analgesik" (Tabel 4).

\section{Pembahasan}

Hasil dari penelitian yang telah dilakukan di 3 puskesmas di Surabaya menunjukkan pasien kanker perempuan sebanyak 94,4\% dan pasien laki-laki sebanyak 5,5\%; pasien yang menderita penyakit kanker payudara sebanyak 52,7\% dan kanker serviks sebanyak 25\%, hal ini seperti laporan Riset Kesehatan Dasar 2013, yaitu: jumlah kanker terbanyak pada perempuan di Indonesia adalah kanker payudara dan kanker leher rahim [1,2]. Nyeri adalah salah satu gejala yang paling umum dan gejala yang menyedihkan pada pasien kanker. Sebanyak 94\% pasien kanker di Puskesmas merasakan nyeri mereda lebih dari dan sama dengan 50\% setelah menggunakan analgesik. Delapan dari tiga puluh tujuh pasien kanker mengatakan bahwa nyeri nya hilang 100\% setelah mengkonsumsi analgesik. Berbeda dengan di India [10], di Amerika sekitar 90\% dari pasien dapat mencapai kontrol nyeri yang baik dengan mengikuti pedoman pengobatan nyeri. Pengurangan nyeri dapat tercapai dengan digunakannya WHO three-step analgesic ladder tentang penggunaan dosis yang tepat berdasarkan tingkatan nyeri, sebagai berikut: untuk nyeri diberikan analgesik non opioid \pm adjuvant (step 1), untuk rasa nyeri yang meningkat atau menetap diberikan opiod lemah \pm non opioid \pm adjuvant (step 2), untuk nyeri yang lebih hebat atau menetap opiod kuat \pm non opioid \pm adjuvant (step 3) [11,12]. Kekuatan efek analgesik dapat dinyatakan dengan nilai Number Needed to Treat (NNT), semakin kecil nilai NNT menunjukkan efek analgesik yang lebih kuat [13,14]. Adjuvant analgesik adalah jenis/golongan obat yang dapat meningkatkan efek analgesik obat golongan analgesik, yaitu antidepresan, kortikosteroid, agonis 
Tabel 1. Karakteristik Pasien

\begin{tabular}{|c|c|}
\hline Parameter $(\mathrm{N}=36)$ & N (\%) \\
\hline $\begin{array}{l}\text { Jenis kelamin } \\
\text { - Laki-laki } \\
\text { - Perempuan }\end{array}$ & $\begin{array}{l}2(5,6) \\
34(94,4)\end{array}$ \\
\hline $\begin{array}{l}\text { Tingkat pendidikan } \\
\text { - Tidak tamat SD } \\
\text { - Tamat SD/setingkat } \\
\text { - Tamat SMP/setingkat } \\
\text { - Tamat SMA/setingkat } \\
\text { - Tamat perguruan tinggi }\end{array}$ & $\begin{array}{l}7(19,4) \\
8(22,2) \\
10(27,8) \\
9(25,0) \\
2(5,6)\end{array}$ \\
\hline $\begin{array}{l}\text { Tingkat penghasilan } \\
\text { - Tidak memiliki penghasilan } \\
\text { - Kurang dari Rp } 200.000 \\
\text { - Rp } 200.000 \text { - Rp } 500.000 \\
\text { - Rp } 500.000 \text { - Rp } 1.000 .000 \\
\text { - Rp 1.000.000 - Rp } 1.500 .000 \\
\text { - Di atas Rp 1.500.000 }\end{array}$ & $\begin{array}{l}3(8,3) \\
4(11,1) \\
3(8,3) \\
11(30,6) \\
7(19,4) \\
8(22,2)\end{array}$ \\
\hline $\begin{array}{l}\text { Jenis kanker } \\
\text { - Kanker ovarium } \\
\text { - Kanker payudara } \\
\text { - Kanker korpus } \\
\text { - Kanker mata } \\
\text { - Kanker serviks } \\
\text { - Kanker prostat } \\
\text { - Kanker laring } \\
\text { - Lain-lain }{ }^{\mathrm{a}}\end{array}$ & $\begin{array}{l}2(5,6) \\
19(52,8) \\
1(2,8) \\
1(2,8) \\
9(25,0) \\
1(2,8) \\
1(2,8) \\
2(5,6)\end{array}$ \\
\hline $\begin{array}{l}\text { Jumlah siklus terapi } \\
\text { - Belum pernah kemoterapi } \\
\text { - } 1 \text { siklus } \\
\cdot 2 \text { siklus } \\
.4 \text { siklus } \\
\text { - } 6 \text { siklus } \\
\cdot 7 \text { siklus } \\
.9 \text { siklus } \\
\cdot 12 \text { siklus }\end{array}$ & $\begin{array}{l}19(52,8) \\
1(2,8) \\
1(2,8) \\
1(2,8) \\
1(2,8) \\
10(27,8) \\
1(2,8) \\
1(2,8) \\
1(2,8)\end{array}$ \\
\hline $\begin{array}{l}\text { Penggunaan analgesik } \\
\text { - Kombinasi kodein dan parasetamol } \\
\text { - Asam mefenamat } \\
\text { - Natrium diklofenak } \\
\text { - Kodein } \\
\text { - Parasetamol }\end{array}$ & $\begin{array}{l}16(44,4) \\
9(25,0) \\
5(13,9) \\
5(13,9) \\
1(2,8)\end{array}$ \\
\hline
\end{tabular}

Keterangan: ${ }^{a}$ diagnosa yang mengarah pada kanker yaitu, tumor stioma dan peradangan yang mengarah kepada kanker

Tabel 2. Rasa sakit yang paling buruk dialami selama 24 jam terakhir

\begin{tabular}{ll}
\hline Skala nyeri BPI & Jumlah pasien $(\%)$ \\
\hline $1-4$ (ringan) & $31(86,1)$ \\
$5-6$ (sedang) & $3(8,3)$ \\
$7-10$ (berat) & $2(5,6)$ \\
\hline
\end{tabular}


Tabel 3. Rasa sakit yang dialami pasien hari ini (secara umum)

\begin{tabular}{ll}
\hline Skala nyeri BPI & Jumlah pasien (\%) \\
\hline $1-4$ (ringan) & $35(97,2)$ \\
$5-6$ (sedang) & $1(2,8)$ \\
$7-10$ (berat) & 0 \\
\hline
\end{tabular}

Tabel 4. Hambatan pengobatan nyeri dari aspek pasien

\begin{tabular}{lll}
\hline Faktor & Lemah $^{\mathbf{a}}(\mathbf{\%})$ & Kuat $^{\mathbf{b}}(\%)$ \\
\hline Takut akan konsekuensi penggunaan analgesik & $34(94,4)$ & $2(5,6)$ \\
Efek Fisiologi & $29(80,6)$ & $7(19,4)$ \\
Komunikasi & $35(97,2)$ & $1(2,8)$ \\
\hline
\end{tabular}

Keterangan:

${ }^{\mathrm{a}}$ skala $0-2$

${ }^{\mathrm{b}}$ skala $3-5$

adrenergik alfa-2 dan neuroleptik [15]. Pasien dengan nyeri kanker memiliki hambatan pada penggunaan analgesik opioid [16]. Terdapat hambatan-hambatan yang berpengaruh dalam penggunaan analgesik pada pasien kanker, takut akan konsekuensi penggunaan analgesik, efek psikologis dan komunikasi. Namun dalam penelitian ini hambatan pengobatan analgesik dari aspek pasien lemah (sekitar 90\% pasien memberikan skor 0-2).

\section{Kesimpulan}

Profil penggunaan analgesik pada pasien kanker yang menerima perawatan paliatif di Puskesmas Rangkah, Pacarkeling dan Balongsari sudah sesuai dengan pedoman bebas nyeri WHO yaitu step 2 pengobatan untuk nyeri ringan hingga sedang dengan obat yang digunakan kombinasi antara kodein dan parasetamol. Kualitas hidup pasien kanker yang telah menerima perawatan paliatif di Puskesmas sudah cukup baik, sekitar 90\% pasien menyatakan mengalami nyeri ringan dan hambatan pengobatan analgesik dari aspek pasien lemah.

\section{Ucapan terimakasih}

Kepala Puskesmas dan Penanggung Jawab
Harian Poli Paliatif Puskesmas Pacar Keling, Puskesmas Rangkah dan Puskesmas Balongsari yang memberikan kemudahan dalam memperlancar dalam pengambilan data penelitian. Penelitian ini tidak didanai oleh sumber hibah manapun. Seluruh penulis menyatakan tidak terdapat potensi konflik kepentingan dengan penelitian, kepenulisan (authorship), dan atau publikasi artikel ini.

\section{Daftar pustaka}

1. Dewi M. Sebaran kanker di Indonesia, Riset Kesehatan Dasar 2007. Indonesian Journal of Cancer. 2017;11(1): 1-8.

2. Kementrian Kesehatan Republik Indonesia. 2013. Riset Kesehatan Dasar 2013. Kementrian Kesehatan RI. Jakarta: 85-6.

3. Dinas Kesehatan Kota Surabaya. 2014. Laporan Tahunan Dinas Kesehatan Surabaya Tahun 2013. Surabaya.

4. Hui D, Bruera E. A personalized approach to assessing and managing pain in patients with cancer. J Clin Oncol. 2014;32(16):1640-6.

5. Aisyaturridha A, Naing L, Nizar AJ. Validation of the Malay Brief Pain Inventory questionnaire to measure cancer pain. J Pain Symptom Manage. 2006;31(1):13-21.

6. Atkinson TM, Mendoza TR, Sit L, et al. The Brief 
Pain Inventory and its "Pain at its Worst in the last 24 Hours" item: clinical trial endpoint considerations. Pain medicine (Malden, Mass). 2010;11(3):337-46.

7. Cleeland CS. The Brief Pain Inventory: user guide [diunduh 8 Maret 2017]. Tersedia dari: https://www.cancercare.on.ca/common/pages/ UserFile.aspx?fileId=350835.

8. Cleeland CS, Ladinsky JL, Serlin RC, Nugyen CT. Multidimensional measurement of cancer pain: comparisons of US and Vietnamese patients. $J$ Pain Symptom Manage. 1988;3:23-7.

9. Riami PA. Pengembangan kuesioner Ibq-Ii untuk menilai hambatan pasien dalam pengobatan nyeri di support group kanker di Indonesia (tesis). Surabaya: Universitas Surabaya; 2014.

10. Singh H, Banipal RPS, Singh B. Assessment of adequacy of pain management and analgesic use in patients with advanced cancer using the Brief Pain Inventory and Pain Management Index calculation. Journal of global oncology. 2017;3(3):235-41.
11. World Health Organization. Cancer [diunduh 8 Maret 2017]. Tersedia dari: http://www.who. int/cancer/palliative/painladder/en/.

12. Bandieri E, Romero M, Ripamonti CI, et al.. Randomized trial of low-dose morphine versus weak opioids in moderate cancer pain.J Clin Oncol. 2016;34(5):436-42.

13. Katz N, Paillard FC, Van Inwegen R. A review of the use of the number needed to treat to evaluate the efficacy of analgesics. J Pain. 2015;16(2):116-23.

14. Bandolier. Oxford league table of analgesics in acute pain [diunduh 18 Juli 2018]. Tersedia dari: http://www.bandolier.org.uk/booth/painpag/ Acutrev/Analgesics/Leagtab.html.

15. Lussier D, Huskey AG, Portenoy RK. Adjuvant analgesics in cancer pain management. Oncologist. 2004;9(5):571-91.

16. Jacobsen R, Møldrup C, Christrup L, Sjøgren P, Hansen OB. Psycological and Behavioural Predictors of Pain Management Outcomes in Patients With Cancer. Scand J Caring Sci. 2010;24(4):781-90. 


\section{Lampiran 1. Alat ukur nyeri Brief Pain Inventory (BPI)}

\section{No Alat ukur nyeri Brief Pain Inventory (BPI)}

1 Selama kita hidup, kebanyakan dari kita pernah merasakan rasa sakit yang biasa dialami (seperti sakit kepala ringan, terkilir, dan sakit gigi). Apakah anda merasakan rasa sakit yang bukan rasa sakit biasa seperti contoh di atas yang anda alami pada hari ini?
1) Ya
2) Tidak

2 Pada diagram di bawah ini, arsirlah area dimana anda merasakan sakit. Beri tanda X pada area yang paling sakit.
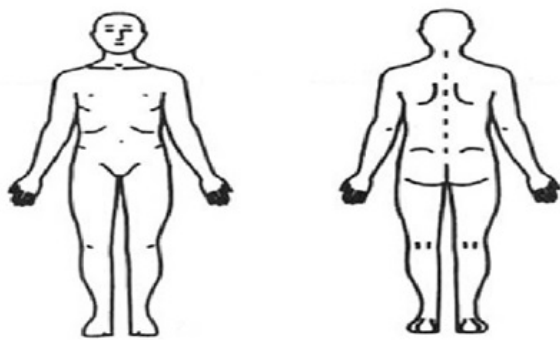

Pada pernyataan no 3-6 ( 0 = tidak sakit; $10=$ sakit terburuk yang anda bisa bayangkan $)$

3 Beri rata-rata nilai rasa sakit yang anda rasakan dengan melingkari satu angka yang paling menggambarkan rasa sakit yang paling buruk yang anda alami dalam kurun waktu 24 jam terakhir pada skala di bawah ini.

0123456678910

$4 \quad$ Beri rata-rata nilai rasa sakit yang anda rasakan dengan melingkari satu angka yang paling menggambarkan rasa sakit yang paling ringan yang anda alami dalam 24 jam terakhir pada skala di bawah ini

$0 \begin{array}{llllllllllll}0 & 1 & 3 & 4 & 5 & 6 & 7 & 8 & 9 & 10\end{array}$

5 Beri rata-rata nilai rasa sakit yang anda rasakan dengan melingkari satu angka yang paling menggambarkan rasa sakit yang anda alami hari ini (secara umum) pada skala di bawah ini

$0 \begin{array}{lllllllll}0 & 2 & 3 & 5 & 6 & 8 & 8 & 10\end{array}$

6 Beri rata-rata nilai rasa sakit yang anda rasakan dengan melingkari satu angka yang paling menggambarkan rasa sakit saat ini (sekarang) pada skala di bawah ini

0123345678910

7 Perawatan atau pengobatan apa yang anda terima untuk mengatasi rasa sakit anda?

8 Dalam 24 jam terakhir, seberapa besar pengaruh perawatan atau pengobatan dalam meringankan rasa sakitnya? Lingkarilah salah satu persentase yang paling menggambarkan seberapa besar rasa sakit itu mereda.

$0102030405060708090 \quad 100 \%$

Tidak mereda

Benar-benar mereda

Pada pertanyaan no 9 poin A-G ( 0 = tidak mengganggu; 10 = benar-benar mengganggu $)$

9 Lingkari satu angka yang menggambarkan bagaimana rasa sakit tersebut mengganggu anda dalam kurun waktu 24 jam terakhir pada hal-hal tersebut ini:

A. Kegiatan sehari-hari

0122345678910

B. Suasana hati

$0 \begin{array}{lllllllll}0 & 1 & 2 & 4 & 5 & 6 & 8 & 9 & 10\end{array}$

C. Kemampuan berjalan

$0 \begin{array}{lllllllll}0 & 1 & 2 & 4 & 5 & 6 & 7 & 8 & 9\end{array}$

D. Pekerjaan normal (termasuk pekerjaan di luar rumah dan pekerjaan rumah tangga)

0122345678910

E. Hubungan dengan orang lain

$0 \begin{array}{llllllllll}0 & 1 & 2 & 3 & 4 & 6 & 7 & 8 & 9 & 10\end{array}$

F. Tidur

$0 \begin{array}{lllllllll}0 & 1 & 2 & 4 & 5 & 6 & 8 & 9 & 10\end{array}$

G. Kenyamanan hidup

$\begin{array}{lllllllllll}0 & 1 & 2 & 3 & 4 & 5 & 6 & 7 & 8 & 9 & 10\end{array}$ 
Lampiran 2. Kuesioner hambatan-hambatan pengobatan nyeri Indonesian Barrier Questionnaire (IBQ)

Kami ingin memahami pandangan anda terhadap nyeri kanker. Dari setiap pertanyaan dibawah ini pilihah angka $0,1,2,3,4$, atau 5 yang menu-

\begin{tabular}{|c|c|c|c|c|c|c|}
\hline \multirow{2}{*}{\multicolumn{7}{|c|}{$\begin{array}{l}0 \text { = Sangat tidak setuju } \\
1 \text { = tidak setuju }\end{array}$}} \\
\hline & & & & & & \\
\hline \multicolumn{7}{|l|}{$2=$ ragu-ragu } \\
\hline \multicolumn{7}{|l|}{3 = setuju } \\
\hline \multicolumn{7}{|l|}{4 = sangat setuju } \\
\hline 5 = Amat sangat setuju & & & & & & \\
\hline
\end{tabular}

Faktor: Takut akan konsekuensi penggunaan analgesik

1. Menggunakan obat nyeri dapat membahayakan sistem kekebalan tubuh kita

2. Tanpa anda sadari obat nyeri membuat anda melakukan ataupun mengatakan hal-hal memalukan

3. Jika anda menggunakan obat nyeri ketika anda merasa sedikit nyeri, maka obat tersebut tidak akan berefek sama baiknya ketika rasa nyeri itu memburuk

Faktor: Efek Fisiologi

4. Obat nyeri dapat merusak sistem kekebalan tubuh saya

5. Lebih mudah untuk bertahan merasakan nyeri dibandingkan merasakan efek samping yang ditimbulkan obat nyeri tersebut

6. Jika sekarang saya menggunakan obat nyeri, obat itu tidak akan bekerja dengan baik jika saya membutuhkannya di kemudian hari

7. Obat nyeri dapat menutupi perubahan pada kondisi kesehatan saya

Faktor 3: Komunikasi

8. Dokter akan merasa saya menjengkelkan apabila saya mengeluhkan soal nyeri yang saya rasa

9. Dengan mengeluh nyeri, dapat mengalihkan konsentrasi dokter terhadap penyembuhan penyakit saya

10. Jika saya bicara tentang nyeri, maka orang-orang akan berfikir saya terlalu banyak mengeluh

Faktor 'Takut akan konsekuensi penggunaan analgesik', dengan nilai chron bach alfa 0,854 terdiri dari tiga item pertanyaan, yaitu: 1 . Menggunakan obat anti-nyeri dapat membahayakan sistem kekebalan tubuh kita, 2. Obat anti-nyeri membuat Anda mengatakan atau melakukan halhal yang memalukan, 3. Jika Anda menggunakan obat anti-nyeri ketika Anda mendapatkan nyeri, maka obat tersebut mungkin tidak bekerja sama baiknya jika nyeri tersebut memburuk.
Faktor 'Efek Fisiologi', dengan nilai chron bach alfa 0,868 terdiri dari 4 item pertanyaan, yaitu: 1 . Obat anti-nyeri dapat merusak sistem kekebalan tubuh Anda, 2. Lebih mudah untuk menghadapi rasa nyeri daripada efek samping yang didapat dari obat anti-nyeri, 3. Jika Anda menggunakan obat anti-nyeri sekarang, obat tersebut tidak akan bekerja sama baiknya jika Anda membutuhkannya nanti, 4. Obat anti-nyeri dapat menutupi perubahan kesehatan Anda. 
Faktor 'Komunikasi', dengan nilai chron bach alfa 0,863 terdiri dari tiga item pertanyaan, yaitu: 1. Dokter mungkin merasa terganggu jika diberitahu tentang nyeri, 2. Melaporkan nyeri dapat mengalihkan perhatian seorang dokter dari menyembuhkan penyakit, 3. Jika saya bicara tentang nyeri, maka orang lain akan berpikir saya adalah seorang pengeluh. 